\title{
QUE MATEMÁTICA ENSINAR ÀS CRIANC̦AS? O PROGRAMA MÍNIMO EM TEMPOS DAS PEDAGOGIAS NÃO DIRETIVAS
}

\author{
Wagner Rodrigues Valente* \\ Universidade Federal de São Paulo (UNIFESP), São Paulo - SP, Brasil
}

RESUMO: O presente estudo analisa o tema dos programas de ensino no contexto das pedagogias não diretivas. Coloca como problemática a compatibilização do ideário de atendimento aos interesses e às necessidades dos alunos face à imposição dos programas. Restringe essa temática ampla considerando os ensinos de matemática. Toma por questão central a interrogação: que matemática ensinar para atender aos interesses e às necessidades dos alunos em tempos das pedagogias não diretivas? Analisa o papel de Lourenço Filho em São Paulo e no Rio de Janeiro, na década de 1930, lançando mão de ferramental da História Cultural, analisando diferentes tipos de documentação. Conclui que o Instituto de Educação do Rio de Janeiro transforma-se em verdadeiro laboratório para elaboração de um programa de ensino de matemática - programa mínimo - em bases vindas da psicologia experimental, a partir das ações de Lourenço Filho iniciadas na Diretoria de Ensino do Estado de São Paulo.

Palavras-chave: Programa Mínimo. Lourenço Filho. Alfredina Souza. Currículo de matemática. História da educação matemática.

\section{WHICH MATHEMATICS SHOULD WE TEACH KIDS? THE "PROGRAMA MÍNIMO" IN TIMES OF NON-DIRECTIVE PEDAGOGY}

ABSTRACT: This study analyzes the educational programs' topic in a nondirective pedagogy context. The research's question is how to reconcile the ideal of service to the students' interests and needs and programs' imposition. The present work restricts this broad topic to mathematics teaching. The paper takes as a central issue the question: Which mathematics should we teach to meet the students' interests and needs in times of non-directive pedagogies? This work also analyzes Lourenço Filho's role in São Paulo and Rio de Janeiro in the 1930s through the use of Cultural History tools, by analyzing official documentation, educational journals and school districts'

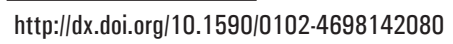

"Livre Docente em Educação pela Universidade Federal de São Paulo (UNIFESP). Professor pesquisador do CNPq e coordenador do GHEMAT - Grupo de Pesquisa de História da Educação Matemática. E-mail: <ghemat.contato@gmail.com>. 
reports. The investigation concludes that the Instituto de Educação do Rio de Janeiro becomes an actual laboratory for the preparation of a math teaching program - Programa Mínimo - based on experimental psychology, initiated by Lourenço Filho in São Paulo State's Education Board.

Keywords: Programa Mínimo. Lourenço Filho. Alfredina Souza. Math curriculum. History of mathematics education.

\section{CONSIDERACְ̃̃ES INICIAIS}

No período compreendido pelas décadas de 1920 a 1940, surgem no cenário nacional correntes pedagógicas múltiplas que, na História da Educação, ganham a caracterização de Movimento da Escola Nova. Tal rubrica abriga pedagogias consideradas não diretivas, num amplo espectro de orientações para o ensino; pedagogias que se servem de outros saberes, entre eles, os da psicologia, para apregoar uma educação que não tenha o professor como centro do processo educativo; pedagogias que se orientam, de um modo ou de outro, pelo que são considerados "as necessidades e os interesses dos alunos". Tais necessidades e interesses serão entendidos, inventariados e classificados por elementos trazidos da leitura que os educadores fazem de outros estudos, sobretudo aqueles vindos da psicologia experimental.

Nesse cenário, há uma questão a ser abordada em tempos de pedagogias não diretivas: a dos programas de ensino. Como compatibilizar o ideário das necessidades dos alunos e de seus interesses com a imposição de um programa de ensino? Essa questão ampla, neste texto, pretende ser abordada de modo mais preciso e específico em termos dos ensinos de matemática. Desse modo, a problemática a ser tratada neste estudo envolve a educação matemática em tempos de pedagogias não diretivas. Assim, considera-se a questão: que matemática ensinar para atender aos interesses e às necessidades dos alunos?

O trabalho trata a questão considerando somente a década de 1930, tendo em vista que nesse período, ao que tudo indica, surgiram os primeiros debates e propostas sobre a elaboração de um programa mínimo para o ensino. O estudo, ainda, atém-se às ações de Lourenço Filho ${ }^{1}$.

\section{A PSICOLOGIA EXPERIMENTAL, A PEDAGOGIA E OS PROGRAMAS DE ENSINO}

Umdosícones do novo tempo escolar, apropriado pelas pedagogias não diretivas, são os testes mentais. Uma referência maior sobre o assunto é Alfred Binet. Com ele, as questões escolares não tardam a ganhar espaço 
em meio à criação dos modos de medir capacidades mentais e as questões escolares envolvem a preocupação com os programas de ensino. Binet, em estudo junto com seu parceiro Théodore $\operatorname{Simon}^{2}$, pondera:

Ocupando-nos em traçar a linha da evolução da inteligência na criança, nós fomos naturalmente levados a dar uma olhada nos programas de ensino, e a constatar que alguns desses ensinos são muito precoces, ou seja, mal adaptados à receptividade mental dos jovens. Em outros termos, as relações de evolução intelectual das crianças com o programa de ensino constituem um novo problema, transplantado sobre o primeiro, e cujo interesse prático é grande (BINET; SIMON, 2010 [1905], p. 67).

De fato, para além dos testes mentais, da revolução trazida pela psicologia sobre o conhecimento do sujeito que aprende, os programas de ensino entram na berlinda e passam a ser questionados.

Nesse sentido, o tema dos programas de ensino será tratado também por outro expoente da pedagogia com base na psicologia experimental, o não menos conhecido Edouard Claparède ${ }^{3}$, que assim se pronuncia, em 1919, em texto intitulado "As novas concepções educativas e sua verificação pela experiência": "Os métodos e os programas gravitando em torno da criança, e não a criança que gira ao redor de um programa imposto, sem poder contar com ele, tal é a revolução copernicana na qual o educador é convidado a adentrar" (CLAPARÈDE citado por HAMELINE, 2010, p. 21).

Assim, o próprio âmbito da psicologia experimental aponta para a questão dos programas de ensino. Conhecer a criança, conhecer a sua psicologia leva aos temas escolares e, entre eles, os programas ganham destaque.

Se a psicologia experimental aponta para a necessidade de repensar os programas de ensino, não será ela, por si só, que irá promover a elaboração de novas diretrizes educativas para o ensino. Caberá às leituras - às apropriações ${ }^{4}$ - que a pedagogia fará dos estudos da psicologia experimental essa tarefa.

A questão dos programas de ensino, tendo em vista a psicologia experimental, é apropriada pela pedagogia. Em nosso meio, essa questão ganha o centro das atenções com Lourenço Filho, expoente maior do movimento escolanovista no Brasil e autor de Introdução ao estudo da Escola Nova, obra reconhecida internacionalmente.

Dantes se ensinava por matérias, por séries de conhecimentos, entre si relacionados pela lógica do adulto. E tudo isso, separadamente. A psicologia vem demonstrando que tal ensino atenta contra leis gerais da atividade psicológica, contra a evolução genética, contra a ação coordenadora dos interesses naturais da criança. Ao invés de matérias, assim, separadas, propõe a psicologia que se ensine por séries de problemas, que globalizem os conhecimentos que se querem (sic.) ver produzidos (LOURENÇO FILHO, 1930a, p. 46). 
Há necessidade, então, de mudar os programas, de reorganizar os ensinos, e isso não é algo que diga respeito somente aos métodos; refere-se, também, aos conteúdos escolares. O que ensinar? Em que seriação? E a pergunta fundamental: como graduar os conhecimentos escolares de modo que eles sejam compatíveis com os novos ensinamentos vindos da psicologia da criança? No caso da matemática, essas questões tornam-se ainda mais claramente postas: como substituir a organização lógica dos conteúdos matemáticos, estruturada na matemática escolar vinda de décadas e décadas anteriores, pela "sistematização psicológica" do que deveria ser ensinado?

A proposta do ensino globalizado considerada por Lourenço Filho ("que se ensine por séries de problemas, que globalizem os conhecimentos que se querem (sic.) ver produzidos"), mencionada anteriormente, precisa ser equacionada com a necessidade da escola graduada. O autor, então, traz a solução para a equação: o programa mínimo. E esse programa está diretamente vinculado à estandardização dos conhecimentos, à sua padronização, definindose quais deverão ser aprendidos em cada etapa escolar:

Esse programa encara, sobretudo, a questão das técnicas fundamentais, leitura, cálculo e escrita, fixando a performance mínima, exigível em cada grau de ensino. [...] Os programas mínimos são de evidente necessidade no ensino graduado: comportam a verificação do ensino por testes, definem a responsabilidade dos docentes, permitem fácil verificação do trabalho (LOURENÇO FILHO, 1930a, p. 198).

Essas considerações são reforçadas em número especial da Revista Escola Nova, em que se exprimem orientações da Diretoria Geral do Ensino de São Paulo, que tem Lourenço Filho como mandatário:

Há cousas, diz muito bem um autor americano, que as crianças têm o direito de aprender, em certa época da vida, e o Estado, obrigado a ensinar, pelos mestres que mantém ao serviço da comunidade. E não é só. O ensino graduado, necessidade de organização administrativa, que ninguém discute, repousa no critério da medida do ensino, em cada período letivo. Os programas, se são um mal, são um mal necessário, ao menos nas escolas graduadas. [...] As técnicas fundamentais da leitura, escrita e cálculo, os hábitos da higiene ou de defesa da saúde, as normas de polidez, as noções gerais de vida doméstica e social, a compreensão dos direitos e deveres cívicos (digamos, assim, o hábito de pensar como brasileiro) tudo isso deve ser comum a todas as escolas, ao ensino de todos os mestres (LOURENÇO FILHO, 1930b, p. 82-83).

É notável o esforço de Lourenço Filho em buscar compatibilizar a existência de um programa de ensino, diante da não diretividade escolanovista. Esse esforço, como se mencionou anteriormente, aponta para a existência de um programa mínimo. Ainda nas orientações da Revista Escola Nova, diz Lourenço Filho (1930b, p. 84): 
Sobre esse programa minimo fundamental, envolvendo-o, dando-lhe vida e significação, situando-o no tempo e no espaço, cada escolar deverá ter o seu programa de desenvolvimento e adaptação, que só o professor pode compor, estudando o meio em que age, compreendendo-o e sendo digno dele. A escola pública precisa ensinar a ler e a escrever, a contar; mas necessita de adaptar também cada novo elemento social, ao pequeno meio em que vive, de modo a torná-lo mais capaz, mais útil a si e à coletividade.

As propostas e orientações de Lourenço Filho atribuem ao professor a condição de elaboração dos novos programas. Como menciona, somente o professor poderá construir o melhor programa, tendo em conta o meio em que age: "Eis a razão por que começamos por pedir, aos professores das escolas reunidas e grupos escolares, que compusessem os seus próprios programas para 1931" (LOURENÇO FILHO, 1930b, p. 84). A não diretividade passa a ser entendida como uma não imposição oficial de um programa, deixado para ser elaborado pelas escolas, pelos seus professores, melhores conhecedores dos alunos, dos níveis de desenvolvimento que apresentam face aos testes e à organização das salas de aula.

A pesquisadora Regina Gualtieri (2013) considera, concordando com a opinião de Almeida Junior ${ }^{5}$, que essa posição de Lourenço Filho constituiu uma estratégia inicial:

Considerando o contexto do administrador, Almeida Junior perguntava: 'como impor aos professores uma técnica que eles desconhecem? Como exigi-la sem prévia adesão interior da parte deles?' Seu entendimento foi de que 'a fim de preparar essa adesão e de incentivar o estudo, Lourenço filho solicitou que cada professor apresentasse o seu próprio programa, 'dentro dos velhos ou dos novos moldes'. E só depois disso, o então diretor geral 'iniciou a catequese através da Escola Nova' (GUALTIERI, 2013, p. 203).

Assim, nos novos tempos, os professores e as escolas deveriam organizar os seus próprios programas de ensino. Num momento posterior, as referências para os programas viriam de experimentos e trabalho de especialistas, tudo em conformidade com elementos apropriados da psicologia experimental. Dela seriam extraídas referências que permitiriam classificar os alunos segundo o seu nível mental, agrupando-os em classes homogêneas, e a montagem das classes constituiria ingrediente definidor do que seria ensinado. Para além disso, haveria uma estandardização das provas e dos exames, para verificação da marcha da eficiência do ensino dos mestres. Em tese, essa seria, ao que tudo leva a crer, a perspectiva do trabalho de Lourenço Filho. No entanto, um ano depois, o educador/ administrador do ensino acaba por deixar o seu cargo em São Paulo... 


\section{SOB NOVA DIREÇÃO, O ANTIGO PROGRAMA DE ENSINO}

Ao que tudo indica, após a saída de Lourenço Filho da Diretoria Geral de Ensino, houve recuo nas propostas feitas por esse educador/administrador. Se no início as escolas desenvolveriam ações para a elaboração dos próprios programas de ensino, consoantes com a solicitação inicial do Diretor Geral, os novos mandatários reoficializaram o programa de ensino em voga a partir de 1925. Essa é uma leitura possível de ser feita a partir dos Relatórios das Delegacias Regionais de Ensino do Estado de São Pauló ${ }^{6}$.

Em relatório da Delegacia Regional de Ensino de Guaratinguetá, leem-se as seguintes considerações:

Em 1930, na administração do Sr. Dr. Lourenço Filho, iniciou-se forte propaganda das novas ideias de educação e tentou-se, pela primeira vez, a elaboração dos programas pelos próprios educadores. A experimentação, conforme tivemos oportunidade de verificar, não falhou, produziu os seus resultados. É verdade que houve muitos senões naturalíssimos em trabalhos de tal monta. Entretanto, parece-nos que tal tarefa deveria continuar a cargo dos mestres, controlados por uma comissão de técnicos. Em 1933 fizemos também a nossa experiência: realizamos um inquérito social na Região, com a esperança de aproveitar os elementos informativos para traçar um plano de trabalho no ano seguinte. [...] O nosso trabalho ficou, apenas, no inquérito, porque recomendações superiores determinaram a execução do programa oficial de 1925 (RELATÓRIO DE GUARATINGUETÁ, 1937).

Também em relatório da Delegacia Regional de Ensino de Itapetininga, há menção sobre as determinações de Lourenço Filho:

Países existem, como a Espanha, em que cabe ao professor a organização do programa da sua escola. Aqui em S. Paulo, em 1931, em obediência à determinação do professor Lourenço Filho, então Diretor do Ensino, teve cada professor de organizar o seu programa. Isso em 1931. No ano seguinte, voltou-se de novo ao programa de 1925 . Hoje segue-se aqui na região, como nas demais do Estado, o programa mínimo de 1934, que, não obstante sua organização nos moldes tradicionais, com discriminação de materiais, honra aos que o organizaram (RELATÓRIO DE ITAPETININGA, 1937).

Assim, estratégia de Lourenço Filho de deixar as escolas e os professores elaborarem os seus programas de ensino não avança, não "faz escola" nas relações mantidas pelo órgão normativo do ensino e as rede de ensino, tendo em vista a saída do educador da Diretoria Geral do Ensino paulista em novembro de 1931.

Em 18 de julho de 1934, o Diário Oficial do Estado de São Paulo publicou o "Projeto de Programa Mínimo para o Curso Primário", assinado pelo Diretor de Ensino Francisco Azzi. A publicação do projeto, elaborado por uma Comissão, aguardou por um mês 
"as modificações que os professores e autoridades pedagógicas [queriam] propor, com o intuito de aperfeiçoá-lo" (DIRETORIA DO ENSINO, 1934). O projeto tinha por referência a manutenção do programa de 1925. Na "Introdução" do documento lê-se: "Na elaboração deste programa não houve o deliberado propósito de subordiná-lo a determinada orientação individual ou adaptá-lo a qualquer dos tipos escolares abrangidos pela genérica denominação de "escola nova"'. Essas considerações têm o fim de justificar a nova designação dos termos "programa mínimo"; ele nada tem a dever às ideias anteriores defendidas por Lourenço Filho. O projeto de um programa mínimo justifica-se, nos termos do documento, pois

a redução do tempo de aula a três horas diárias, motivada pela carência de prédios escolares, impediu a integral execução desse programa [o de 1925]. Por isso, a Diretoria do Ensino resolveu estabelecer um programa mínimo, destinado especialmente aos grupos escolares que funcionam em três períodos (SECRETARIA DOS NEGÓCIOS..., 1941)

Em 12 de dezembro de 1934, o então Diretor do Ensino, Luiz Mota Mercier, comunicou a oficialização do Programa Mínimo, elaborado pelo projeto de seu antecessor. Tal programa foi ratificado em 30 de abril de 1935, pelo Secretário da Educação e Saúde Pública de São Paulo à época, Cantídio de Moura Campos, nos seguintes termos:

O Secretário da Educação e Saúde Pública resolve manter nos grupos escolares o programa aprovado por ato de 19 de fevereiro de 1925 do Secretário de Estado dos Negócios do Interior, e determina que nos grupos escolares tresdobrados seja observado o Programa Mínimo que a este acompanha, do qual se escolherão os pontos de exame de todos os grupos escolares do Estado (SECRETARIA DOS NEGÓCIOS..., 1941).

Se os termos eram os mesmos - a necessidade de um programa mínimo -, o conteúdo deles era diverso. $\mathrm{Na}$ estratégia de Lourenço Filho, no dizer de Almeida Júnior, como se viu anteriormente, haveria um momento de liberdade aos professores para que repensassem os programas. A hipótese plausível era que, durante esse tempo, depuradas as singularidades, os programas iriam convergir para os temas já apregoados por Lourenço Filho como essenciais para o curso primário. No entanto, a reafirmação do programa de 1925 consolidou, ao que parece, as referências que o professorado paulista seguia em termos de normatização de seus ensinos. Passado um primeiro momento de experimentação, por algumas escolas, da proposta de Lourenço Filho, o cotidiano escolar de todas as instituições se via regido, novamente, por um único documento oficial. 
O programa de 1925 constitui um verdadeiro guia para o desenvolvimento de uma pedagogia intuitiva. Em particular, isso é notável para os ensinos de matemática. O programa de 1925 aponta para uma graduação do ensino intuitivo ano a ano escolar. Publicado originalmente no Diário Oficial do Estado de São Paulo, em $1^{\circ}$ de março de 1925, o documento, para cada uma das matérias, contém indicações para o ensino e o programa propriamente dito. No caso da aritmética, tem-se um extrato como segue:

\footnotetext{
Indicações - $\mathrm{O}$ ensino de aritmética no $1^{\circ}$ ano será intuitivo e prático constando de rudimentos das quatro operações sobre números que não excedam da primeira centena. Em lugar, porém, de fazer o aluno decorar e escrever mecanicamente a série de números de 1 a 100, exercício que de maneira alguma põe em atividade as suas faculdades de atenção e reflexão, o mestre deverá ensinar progressivamente o valor de cada número em suas relações com os números inferiores, já conhecidos do aluno, fazendo-o observar, comparar, raciocinar. [...]
}

Programa 1) Ensinar, por meio de grupos de objetos, os números 1 a 10. Exercícios concretos, cálculos com o auxílio de estampas e problemas orais com esses números, abrangendo as quatro operações. Noção de dobro e metade (Como exemplo concreto, mostrar o litro, o meio litro e o duplo litro) [...] (SECRETARIA DE ESTADO..., 1925).

Passo a passo, o documento dá indicações metodológicas de trato dos conteúdos, "conversa com os professores", orienta sobre o uso de materiais didáticos, seleciona e faz uma graduação dos conteúdos ano a ano escolar. Trata-se de um verdadeiro programa para o ensino intuitivo, em todas as séries, e de um programa extremamente diretivo: conteúdos, métodos, materiais de ensino, entre outros elementos, são cuidadosamente colocados à disposição dos professores para o ensino no curso primário.

\section{LOURENÇO FILHO NO RIO DE JANEIRO: EM BUSCA DE UM PROGRAMA MÍNIMO NÃO DIRETIVO}

Considerada a indicação de Lourenço Filho de deixar para as escolas e os professores a construção dos programas de ensino, de outra parte, em anos seguintes, o mesmo autor promoveu ações de modo a cientificamente organizar o que deveria constar num programa mínimo. E isso foi feito no Rio de Janeiro.

Deixando São Paulo, entre os anos de 1932 e 1937, a convite de Anísio Teixeira, então à frente da administração da instrução pública carioca, Lourenço Filho iria dirigir o Instituto de Educação do Rio de Janeiro. $\mathrm{Na}$ análise do papel desse instituto, a historiadora da educação Diana Vidal (2000, p. 80) considera que 
A própria ideia de constituição de um Instituto de Educação relacionava-se à concepção de ensino laboratorial em um duplo sentido: ensino experimental e aluno experimentador. Aglutinando, de forma integrada, as Escolas de Professores Secundárias e Primárias e o Jardim de Infância servia como um campo de experimentação e observação do aluno, com vistas a destacar elementos para a construção de uma ciência da criança. Atuando como um campo de reflexão sobre a prática educativa, favorecia a revisão constante dos métodos aplicados por docentes e alunos na Escola de professores.

A mesma historiadora avalia, considerando a leitura dos escritos de Anísio Teixeira à época, que este educador

defendia que formar professores era desenvolver-lhes a atitude científica, preparálos para os desafios do profissional, munindo-os de um saber técnico específico, de um instrumental de análise capaz de subsidiá-los na resolução de problemas práticos e na realização de pesquisas (VIDAL, 2000, p. 86)

De fato, o espírito de pesquisa parece ter sido levado adiante no instituto. Ainda de acordo com Diana Vidal (2000, p. 82), “os docentes $[\ldots]$ ainda eram incitados a publicar seus programas e analisar sua prática docente em artigos editados na revista Arquivos do Instituto de Educação". Essa revista, criada por Lourenço Filho em 1934, tinha por objetivo, de acordo com seu primeiro número, "registrar e divulgar trabalhos e investigações sobre o ensino e organização escolar, realizados no Instituto de Educação, do Rio de Janeiro, Brasil” (ARQUIVOS..., 1934, p. 3). Nesse periódico é possível ler como, mais incisivamente, vai sendo configurado um programa mínimo de ensino de matemática para os primeiros anos escolares, em boa parte, fruto das pesquisas da professora Alfredina de Paiva e Souza.

Alfredina de Paiva e Souza, carioca, nascida em 1905, concluiu a Escola Normal do Distrito Federal em 1923; ingressou no Instituto de Educação do Rio de Janeiro em 1932 (ALMEIDA, 2013, p. 45). Alfredina trabalhou na Seção de Prática de Ensino do Instituto entre os anos de 1932 a 1937 (LOURENÇO FILHO, 1945). Consoante com os incentivos e os objetivos do instituto, Alfredina publicou os resultados de suas experiências no periódico Arquivos do Instituto de Educação, do Rio de Janeiro, em junho de 1936. O título de sua pesquisa é "O ensino da Matemática no curso primário - adição e subtração”. Consideremos o seu texto como exemplo importante das iniciativas que visavam construir um programa sob a ótica da psicologia experimental.

Alfredina Souza inicia o seu texto fazendo referência a um passado a ser superado no ensino das quatro operações fundamentais da aritmética:

Fazia-se, outrora, o ensino das combinações fundamentais das quatro operações, por simples decoração, quase sempre cantada e desprovida de interesse direto. 
As combinações eram apresentadas segundo a ordem crescente de valores, facilitando a memorização, que precedia a compreensão e era feita antes que as crianças sentissem, em situações reais, a necessidade dos conhecimentos respectivos (SOUZA, 1936, p. 181)

Esse expediente didático-pedagógico precisava ser alterado, e isso deveria ser feito experimentalmente, construindo testes. No dizer de Alfredina Souza, no que diz respeito ao conteúdo a ser ensinado, de modo que possa de fato ser aprendido, é preciso:

[...] examinar as 100 combinações fundamentais de cada operação, procurando descobrir as falhas mais frequentes em que os alunos incidem, conseguindo assim grupá-las de forma a permitir ao professor uma organização e distribuição mais eficiente do treino. Claro está que as causas múltiplas e complexas dessas falhas dificilmente poderiam ser pesquisadas, e somente a atenção diária e constante de cada professor, em presença da classe, poderia talvez fornecer os elementos suficientes para um diagnóstico seguro. Por outro lado, a organização do treino em um novo sentido, com orientação mais definida, conduzir-nos-ia, em breve, a uma completa modificação na escala de dificuldades, agora encontradas (SOUZA, 1936, p. 181).

Com esses pressupostos, Alfredina Souza passa a descrever a pesquisa realizada, sua experiência pedagógica e o encontro dos resultados, no melhor e mais acabado estilo dos novos tempos da era dos testes. E, mais, aponta o professor e pesquisador Frank Clapp, dos Estados Unidos, como inspirador do trabalho que ela realiza no Brasil, semelhante àquele feito em terras do norte.

Todos os cuidados do processo experimental são descritos por Alfredina Souza:

Para que todas as crianças começassem ao mesmo tempo, as fórmulas foram dobradas na parte superior, ficando à vista apenas os elementos de identificação. As crianças de $2^{\mathrm{a}}$ série não preencheram os claros relativos à idade, sendo os dados necessários recolhidos nas secretarias das escolas. [...] Para evitar que as crianças deixassem em branco fileiras do trabalho, foi entregue, a cada uma, uma folha de papel em branco que deveria ser colocada abaixo de cada fileira e que serviu, também, para objetivação dos cálculos. Foram adotados todos os cuidados relativos à distribuição do material, exemplificação no quadronegro, marcação do tempo e coleta das fórmulas, para que houvesse a maior uniformidade possível na aplicação do teste (SOUZA, 1936, p. 184).

A experiência foi realizada com alunos de cinco escolas. $\mathrm{Na}$ apuração dos resultados da pesquisa, obteve-se uma classificação das dificuldades em cada série escolar em cinco grupos, a saber: " $1^{\circ}$ ) dificuldade muito pequena - grupo $\mathrm{A} ; 2^{\circ}$ ) dificuldade pequena - grupo $\mathrm{B} ; 3^{\circ}$ ) dificuldade média - grupo $\mathrm{C} ; 4^{\circ}$ ) dificuldade grande - grupo D; $5^{\circ}$ ) dificuldade muito grande - grupo E” (SOUZA, 1936, p. 185). 
Seguem, no texto de Alfredina (SOUZA, 1936), as combinações de operações de adição para cada um dos grupos acima. O mesmo, em páginas posteriores, será feito para a subtração ${ }^{7}$.

Depois de uma série de gráficos de aproveitamento e de referências às dificuldades dos alunos e à graduação delas na realização de operações de adição e subtração, seguem-se as conclusões. Entre essas, descobertas importantes que, por certo, causaram estranheza devido ao modo como vinha sendo pensado o ensino de aritmética nas escolas. A principal delas, nos parece, diz respeito diretamente aos níveis de dificuldade dos alunos ao efetuarem adições e subtrações: dentro de cada nível, as mais diversas combinações de números evidenciando o mesmo nível de dificuldade. Assim, por exemplo, um aluno de 8 anos de idade, na segunda série, teria o mesmo grau de dificuldade para efetuar a operação $1+1$ e para obter o resultado de $5+3$. Trata-se, para esse caso, do nível A, de dificuldade muito pequena. No entanto, se a esse mesmo aluno fosse solicitado efetuar $3+5$, isso representaria um nível de dificuldade maior, recaindo no nível $\mathrm{B}$.

Desse modo, diferentemente de seguir a ordem numérica crescente para o ensino da operação de adição, vê-se que o mais indicado seria seguir a ordem de dificuldade que determinadas combinações de parcelas apresentam. $\mathrm{O}$ mesmo vale para a operação de subtração.

Os resultados obtidos pela professora Alfredina e, por certo, de outras pesquisas pedagógicas realizadas por professores que vinham estudando outras matérias de ensino justificam a divulgação de um programa para a formação de professores, por intermédio de Lourenço Filho, segundo texto publicado pelos Arquivos do Instituto de Educação, em 1937, intitulado $A$ formação do professorado primário, em que é possível ler:

Os programas, que adiante se publicam, pacientemente experimentados, e
ajustados cada ano ao desenvolvimento do nível de preparação dos alunos,
evidenciam o espírito novo, de que se tem procurado embeber todo o trabalho.
[...] Não representam obra definitiva. Exprimem um momento de evolução na
primeira tentativa de renovação do preparo dos mestres primários brasileiros,
que este Instituto vem realizando, malgrado os naturais empecilhos que
haveria de enfrentar. Mas a obra, já realizada em cinco anos, convence de sua
superioridade aos que, de ânimo sincero a queiram conhecer, em suas minúcias
(LOURENÇO FILHO, 1937, p. 293)

O programa elaborado pela professora Alfredina - "Cálculo" -, que na revista aparece logo após o de "Leitura e Linguagem", enumera como estrutura da matéria do curso de formação de professores: "objetivos do ensino da matéria", "requisitos fundamentais para o estudo da matéria", "programa da matéria". 
Em termos dos conteúdos matemáticos a serem ensinados, nenhum estranhamento relativamente àqueles já clássicos temas da aritmética escolar: processos de cálculo, numeração, operações com inteiros, frações ordinárias e decimais, sistema métrico, porcentagem e juros (SOUZA, 1937, p. 323-326). Mas, para além desses conteúdos explícitos, estão presentes itens completamente inovadores para a formação dos mestres. Exposta acima, a própria organização dessa matéria formativa em três itens é inédita. Além disso, é preciso destacar que, no item "programa da matéria", há seis subdivisões, a saber: "Breve resumo da História da Matemática", "Evolução do ensino da Matemática na escola elementar", "Fundamentos psicológicos do ensino do Cálculo", "O Cálculo na escola nova", "Formas gerais de ensino. Relação do Cálculo com outras disciplinas do currículo" e "Exercícios sistematizados e jogos - Problemas Material didático" (SOUZA, 1937, p. 323-326). Em meio ao item "Fundamentos psicológicos...", encontram-se temas a fazer parte da formação dos mestres, como: "problemas que a aprendizagem do cálculo apresenta à Psicologia", "as combinações aprendidas e a transferência", "medida das habilidades em Aritmética".

Em suma: sob essa perspectiva, qualquer professor teria condições de elaborar um programa mínimo para o ensino de matemática nos anos iniciais que representasse a perspectiva não diretiva, calcada na psicologia experimental, em conformidade com os interesses das classes de alunos de uma dada escola. Trata-se também, aqui, de constatação que Gualtieri (2013) apontou no artigo "Liberdade esclarecida: a formação de professores nos anos 1930" em análise que realizou da Revista Escola Nova.

\section{CONSIDERACְ̃̃ES FINAIS}

A discussão sobre o tema dos programas de ensino, do programa mínimo, em face de pedagogias não diretivas neste estudo levou em conta as ações de Lourenço Filho. Um dos principais personagens do movimento da Escola Nova, esse autor deparou-se com a questão dos programas, uma demanda sempre presente em termos das atribuições das diretorias de ensino. Depreendeu-se a possibilidade de não indicação de um programa mínimo expedido sob o mando de Lourenço Filho quando da sua estada em São Paulo ser explicada como uma estratégia: juntamente com a liberdade dos professores e das escolas em estabelecer os programas viria 
um inventário de temas essenciais a compor consensualmente o programa mínimo. Mas ainda cabe outra explicação: houve, à época, a necessidade de aguardar a realização de estudos ainda não efetuados, de modo que pudessem embasar propostas referenciadas por apropriações da psicologia experimental. Esse é nitidamente o caso das propostas para o ensino de matemática. Ao tempo de Lourenço Filho em São Paulo, ao que tudo leva a crer, não havia estudos que pudessem dar subsídios ao educador para expedir programas. No caso da matemática, a esse tempo, a autoridade paulista estava representada por um antigo educador, dos tempos de primeira hora do movimento republicano paulista, alguém que era referência para a prática intuitiva desse ensino: Antonio Firmino de Proença (ALMEIDA, 2013). Não é de se estranhar, assim, a perfeita compatibilidade de reafirmação do programa de 1925 com o contexto da época.

A mudança para o Rio de Janeiro levou o educador paulista a organizar as propostas de ensino cientificamente, isto é, nos moldes de testes pedagógicos, classes homogêneas e avaliação estandardizada, a partir de referências da psicologia experimental. Assim, o Instituto de Educação daquela cidade transformou-se em verdadeiro laboratório para as suas ações. Estas desembocaram em programas mínimos para cada uma das matérias, os quais, totalmente referenciados, "pacientemente experimentados, e ajustados cada ano, ao desenvolvimento do nível de preparação dos alunos, [evidenciavam] o espírito novo, de que se [procurava] embeber todo o trabalho" (LOURENÇO FILHO, 1937, p. 293).

Por fim, é possível dizer que, se em São Paulo, com a saída de Lourenço Filho da Diretoria da Instrução Pública do Estado, a proposta de programa mínimo reforçava programas anteriores, calcados na manutenção de uma organização lógica dos conteúdos matemáticos de ensino, mesmo que sob o manto do método intuitivo, no Rio de Janeiro, o programa mínimo representou uma apropriação dos processos experimentais que deveriam ditar o que e como ensinar matemática nos primeiros anos escolares, em busca de uma organização psicológica desses ensinos.

\section{REFERÊNCIAS}

ALMEIDA, D. H. A matemática na formação do professor primário nos Institutos de Educação de São Paulo e Rio de Janeiro (1932-1938). 2013. 172 f. Dissertação (Mestrado em Ciências). Programa de Pós-Graduação em Educação e Saúde na Infância e na Adolescência, Escola de Filosofia, Letras e Ciências Humanas, Universidade Federal de São Paulo, São Paulo, 2013. 
ARQUIVOS DO INSTITUTO DE EDUCAÇÃO. Rio de Janeiro: Instituto de Educação. Universidade do Distrito Federal. v. 1, n. 1, 1934.

BINET, A.; SIMON, T. (1905). Le développement de l'intelligence chez les enfants. IN: ZAZZO, R. Alfred Binet. Recife: Fundação Joaquim Nabuco, Editora Massangana, 2010. p. 67-69 (Coleção Educadores MEC).

CELESTE FILHO, M. Os relatórios das Delegacias Regionais de Ensino do Estado de São Paulo como fonte de pesquisa para a história da educação - décadas de 1930 e 1940. Rev. bras. hist. educ., Campinas-SP, v. 12, n. 1 (28), p. 71-111, jan./abr. 2012.

CHARTIER, R. A História Cultural: entre práticas e representações. Lisboa: Difel; Rio de Janeiro: Bertrand Brasil, 1990.

DIRETORIA DO ENSINO. Projeto de Programa Mínimo para o Curso Primário. Diário Oficial do Estado de São Paulo, São Paulo, p. 34-41, 18 jul.1934.

GANDINI, R. P. C. Almeida Júnior. Recife: Fundação Joaquim Nabuco, Editora Massangana, 2010. (Coleção Educadores MEC)

GANDINI, R. P. C.; RISCAL, S. A. Manoel Bergström Lourenço Filho. Dicionário de Educadores no Brasil: da Colônia aos dias atuais. Rio de Janeiro: Editora da UFRJ/MEC/ INEP, 1999. p. 365-373.

GUALTIERI, R. C. E. Liberdade esclarecida: a formação de professores nos anos 1930. Revista HISTEDBR On-line, Campinas, n. 52, p. 198-214, set. 2013.

HAMELINE, D. Édouard Claparède (1873-1940). IN: PETRAGLIA, I.; DIAS, E. T. D. M. Édouard Claparède. Recife: Fundação Joaquim Nabuco, Editora Massangana, 2010. (Coleção Educadores MEC)

HOFSTETTER, R.; SCHNEWUWLY, B.; FREYMOND, M. Pénétrer dans la vérité de l'école pour la juger pièces en main' - L'irrésistible institutionanlisation de l'expertise dans le champ pédagogique (XIXe. - XXe. siècles). In: BORGEAUD, P. et al. (dir.) La fabrique des savoirs: Figures et pratiques d'experts. Suisse: Les Éditions Médecine et Hygiène-Georg, 2013. p. 79-116.

LOURENÇO FILHO, M. B. Introdução ao estudo da Escola Nova. São Paulo: Cia. Melhoramentos de São Paulo, 1930a.

LOURENÇO FILHO, M. B. A questão dos programas. Escola Nova, São Paulo, Órgão da Diretoria Geral de Ensino de São Paulo, v. 1, n. 2-3, p. 81-85, nov./dez. 1930 b.

LOURENÇO FILHO, M. B. A formação do professorado primário. Arquivos do Instituto de Educação. Rio de Janeiro: Instituto de Educação. Secretaria Geral de Educação e Cultura. Prefeitura do Distrito Federal. v. 1, n. 3, p. 283-294, 1937.

LOURENÇO FILHO, M. B. Prática de Ensino. Arquivos do Instituto de Educação. Rio de Janeiro: Instituto de Educação. Secretaria Geral de Educação e Cultura. Prefeitura do Distrito Federal. v. 2, p. 35-47, dez. 1945.

RELATÓRIO DE GUARATINGUETÁ. Delegacia Regional de Ensino. 1937. Disponível em: www.arquivodoestado.sp.gov.br/upload/pdfs/RDRGR1936.pdf. Acesso em: 18 jun. 2015. RELATÓRIO DE ITAPETININGA. Delegacia Regional de Ensino. 1937. Disponível em: www.arquivodoestado.sp.gov.br/upload/pdfs/RDRIT1936.pdf. Acesso em: 18 jun. 2015.

SECRETARIA DOS NEGÓGICOS DA EDUCAÇÃO E SAÚDE PÚBLICA. Departamento de Educação. Programa de Ensino para as Escolas Primárias. Anexo Programa Mínimo para o Curso Primário. São Paulo: Serviço Técnico de Publicidade, 1941. SECRETARIA DE ESTADO DOS NEGÓCIOS DO INTERIOR. Ato de $1^{\circ}$ de março de 1925. Programa para os Cursos Primário e Médio. Diário Oficial do Estado de São Paulo, São Paulo, p. 356-376, 1‥ mar. 1925. 
SOUZA, A. P. O ensino de Matemática na escola primária. Arquivos do Instituto de Educação. Rio de Janeiro: Instituto de Educação. Secretaria Geral de Educação e Cultura. Prefeitura do Distrito Federal. v. 1, n. 2, p. 181-222, 1936.

SOUZA, A. P. Cálculo. Arquivos do Instituto de Educação. Rio de Janeiro: Instituto de Educação. Secretaria Geral de Educação e Cultura. Prefeitura do Distrito Federal. v. 1., n. 3, p. 323-326, 1937.

VIDAL, D. G. Prática, experimental e científica: a formação docente na administração Anísio Teixeira da educação carioca (1931-1935). In: SMOLKA, A. L. B.; MENEZES, M. C. (Org.). Anísio Teixeira: provocações em educação. Campinas: Autores Associados; Bragança Paulista: EDUSF, 2000, p. 71-90.

ZAZZO, R. Alfred Binet. Recife: Fundação Joaquim Nabuco, Editora Massangana, 2010. (Coleção Educadores MEC)

\section{NOTAS}

${ }^{1}$ Manoel Bergström Lourenço Filho (1897-1970) tem vastíssima biografia intelectual, tendo ocupado cargos importantes na condução da educação brasileira. Para fins deste texto, ressalte-se que sua trajetória inclui o diploma da Escola Normal de Pirassununga, em 1914; a carreira no magistério como professor primário no Grupo Escolar de Porto Ferreira, em São Paulo; a docência na Escola Normal de Piracicaba, na Escola Normal de Fortaleza e na Escola Normal de São Paulo. Em outubro de 1930, foi nomeado diretor geral da Instrução Pública de São Paulo. Nesse cargo, reorganizou e mudou sua denominação para Diretoria Geral do Ensino. Transformou a Escola Normal da Praça da República em Instituto Pedagógico. Em 1932, passou a dirigir o Instituto de Educação do Distrito Federal. É considerado um dos principais representantes do movimento da Escola Nova no Brasil (GANDINI; RISCAL, 1999).

${ }^{2}$ Binet conheceu Simon em 1892 e com ele trabalhou até o fim de sua vida. Por meio de Simon entrou em contato com crianças anormais na área da psiquiatria e encontrou-se, ainda, com Édouard Claparède (ZAZZO, 2010, p. 132).

${ }^{3}$ Édouard Claparède (1873-1940), psicólogo e pedagogo nascido em Genebra, criou nessa cidade o Instituto J. J. Rousseau (Institut Rosseau - École des sciences de 1 - éducation), em 1912. Trata-se de um instituto privado que reúne pesquisadores e professores que participam de escolas experimentais, as quais servem de laboratórios para melhor conhecimento da infância e de seu desenvolvimento, de modo a ajustar os processos pedagógicos com vistas à melhoria das escolas (HOFSTETTER; SCHNEUWLY; FREYMOND, 2013, p. 90). Entre 1910 e 1915, escreveu vários artigos e difundiu a concepção funcional de educação, em 1911. Em 1930, visitou o Brasil durante a publicação da primeira versão em português do livro A escola e psicologia experimental, na coleção organizada por Lourenço Filho para a Editora Melhoramentos (HAMELINE, 2010).

${ }^{4}$ O conceito de "apropriação" elaborado pelo historiador cultural Roger Chartier (1990) remete aos modos como uma produção é dada a ser lida, a ser utilizada, para além das intenções de sua constituição inicial. Neste presente estudo, interessam os modos como educadores mobilizaram estudos da psicologia experimental para construírem autoridade em suas propostas pedagógicas.

${ }^{5}$ Antonio Ferreira de Almeida Júnior nasceu em Joanópolis, no estado de São Paulo, em 8 de junho de 1892. Almeida Júnior, como ficou conhecido, participou de algumas das mais importantes passagens da história da educação brasileira: em 1920 assessorou Antonio Sampaio Dória, então Diretor do Ensino do Estado de São Paulo, realizando o primeiro 
recenseamento escolar; foi um dos signatários do Manifesto dos Pioneiros da Educação Nova, em 1932; foi Diretor do Ensino Público do Estado de São Paulo durante o período de setembro de 1935 a abril de 1938 (GANDINI, 2010).

${ }^{6}$ Pouco mais de três meses após a criação do Ministério da Educação e Saúde Pública, em março de 1931, foi criada a Secretaria de Estado da Educação e Saúde Pública de São Paulo. Nesse ano e no seguinte, foram organizadas as Delegacias Regionais de Ensino do Estado de São Paulo. As 21 delegacias regionais tiveram como uma de suas incumbências iniciais inventariar todo o sistema escolar paulista de então. Para tanto, de 1933 a 1944, elaboraram ao menos 68 relatórios detalhando a consolidação, durante o período varguista, do aparato de ensino no Estado de São Paulo (CELESTE FILHO, 2012, p. 73).

${ }^{7}$ Um estudo mais aprofundado sobre a presença de Alfredina Souza no Instituto do Rio de Janeiro pode ser lido na dissertação de Almeida (2013).

Recebido: $26 / 10 / 2014$

Aprovado: 06/02/2016

Contato:

Estrada do Caminho Velho, 333, Bairro Pimentas

Guarulhos $\mid$ SP $\mid$ Brasil

CEP 07.252-312 